\title{
Collaboration
}

\section{Report on the Study of Social and Emotional Skills of Chinese Adolescents (III)}

\author{
Yipeng Tang, Jie Zheng, Xiaoxue Sun, \& Jingzhong Huang
}

East China Normal University, Shanghai 200241, China

\begin{abstract}
$\mathrm{C}$
OLLABORATION is essential to social and emotional competence. Accordingly, collaboration has always been considered a key indicator and core accomplishment of students' development. People who excel at collaboration can successfully cooperate with others, reduce interpersonal conflict and achieve the final goal by maintaining a positive attitude. For children and adolescents, greater collaboration means more pro-social behaviors and fewer problem behaviors. Collaboration is also important for students' life development and is closely linked to some life outcome variables, such as educational expectations, health and well-being, according to the OECD. Based on evaluation data out of Suzhou, China, the study under review presents the evaluation results of teenagers' cooperation ability from different dimensions and levels. The authors present the research results from three aspects, including the predictive variable analysis of collaboration ability and the life outcome variable of collaboration ability. Analysis shows that the students' empathy, trust, and cooperation capabilities differ depending on age, gender, urban \& rural areas, and school types; correlation exists in the 15 kind of abilities of the "Big Five Personalities". Through regression analysis from multiple aspects explored the prediction variables; the researchers explored the student's ability of collaboration and cooperation ability in the 5 major categories of life outcome variables. Specific research results are as follows:
\end{abstract}

\section{General Situation of Collaboration Ability}

(C) 2021 Insights Publisher. All rights reserved.

(c) (i) (2) Creative Commons Non Commercial CC BY-NC: This article is distributed under the terms of the Creative Commons Attribution-NonCommercial 4.0 License

(http://www.creativecommons.org/licenses/by-nc/4.0/) which permits non-commercial use, reproduction and distribution of the work without further permission provided the original work is attributed by the Insights Publisher. 
This paper describes the overall performance of students in Suzhou in collaboration ability, showing the score of each sub-ability of collaboration ability, the correlation between collaboration ability and other sub-ability, and the differences of age, gender, urban and rural areas, and school types in collaboration ability. The study found students in Suzhou self-evaluated quite high, and their self-reported empathy, trust, and cooperation abilities were higher than the international average (i.e., more than 500 points). Moreover, the self-evaluation score of the 10-year-old group was significantly higher than that of the 15-year-old group. The correlation between empathy and cooperation was high $(r=0.76$ in the 10 -year-old group, $r=0.75$ in the 15 year-old group). There was a moderate correlation between empathy and trust ( $r=0.51$ in the 10-year-old group, $r=0.53$ in the 15 -year-old group). Trust and cooperation were also moderately correlated $(r=0.55$ in the 10 year-old group, $\mathrm{r}=0.64$ in the 15 -year-old group). Collaboration ability and other social and emotional abilities show a high level of unity, and students who have a high level of collaboration ability tend to have a high level of other abilities. There are significant differences in age, gender, and urban and rural areas in terms of collaboration ability. On the whole, the 10-year-olds were more cooperative than the 15 -year-olds. Boys at age 10 were less cooperative than girls, but the opposite was true at age 15. But for both 10-yearolds and 15-year-olds, inner-city students showed higher levels of collaboration than those from rural areas.

\section{Factors Influencing Collaboration Ability}

The authors used multiple regression to analyze the influence of background variables, students' variables, teachers' variables, school variables and family variables on students' empathy, trust, and cooperation.

With concern to background variables, for the 10-year-old group, the two variables of family possession and family book collection both had stable and significant positive effects on students' cooperative ability $(\mathrm{p}<0.01)$. For the 15-year-old group, parents' highest educational background, family ownership, and family book collection had a stable and significant positive effect on collaboration ability $(\mathrm{p}<0.01)$. In addition, by comparing the coefficients of the three variables, it appears that the influence degree of family ownership is much higher than that of parents' highest educational background and family book collection, and the influence coefficient is up to 0.25. Generally speaking, family ownership and family book collection have consistent and significant influences on the cooperative ability of the two age groups.

As for the student variables, for the 10-year-old group, the five variables of security, friend relationship, good habit friends, indoor activity time, and outdoor activity time all have a stable and significant positive influence on one's cooperative ability. In addition, from the size of the standardized coefficient, the influence degree of the three variables of security, friendship, and habit friends is much higher than the indoor and outdoor activity time, the 
correlation coefficient is higher than 0.10 . For the 15-year-old group, the six variables of security, friend relationship, friends with good habits, indoor activity time, outdoor activity time, and growth thinking have a stable and significant positive impact on the cooperative ability. From the size of the standardization coefficient, the influence degree of security, friendship, and habitual friends is higher than other variables. In addition, high expectations of friends and time spent online had significant negative effects on the 15year-old group ( $\mathrm{p}<0.01, \beta=$ was around -0.06$)$.

Among the teacher variables, for 10-year-old students, teaching age, teacher's education background, and teacher-student relationship all have stable and significant positive effects on a student's collaboration ability ( $\mathrm{p}<$ 0.01 ). For the 15-year-old group, only the teacher-student relationship had a stable and significant positive effect on collaboration ability $(\mathrm{p}<0.01, \beta=$ 0.24 ), while teaching age had no significant effect on trust and cooperation. Teacher's education background had no significant effect on empathy. Overall, the teacher-student relationship had a consistent and significant effect on collaboration in both age groups.

As for school variables, school belonging, school cooperation atmosphere, and off-campus activities all had stable and significant positive effects on collaboration ability for 10 -year-old students $(\mathrm{p}<0.01)$. From the standardized regression coefficient, the degree of school belonging $(\mathrm{p}<0.01 \beta=$ $0.34,0.29,0.39)$ was higher than that of school cooperative atmosphere $(\mathrm{p}<$ $0.01, \beta=0.25,0.24,0.22$ ). The influence degree of cooperative atmosphere in school was higher than that of off-campus activities $(\mathrm{p}<0.01, \beta=0.10$, $0.06,0.10)$. The 15 -year-old group was similar to the 10 -year-old group in that school belonging, school cooperation atmosphere, and off-campus activities had a stable and significant positive effect on their collaboration ability, and school belonging had the highest effect $(\mathrm{p}<0.01, \beta=0.38,0.42$, $0.45)$.

As for the family variables, for the 10-year-old group, the three variables of considerate mother, considerate father, and parents' high expectations all have a stable and significant positive impact on the cooperative ability. In terms of the normalization coefficient, the influence degree of understanding mother ( $p<0.01, \beta=0.15,0.12,0.14)$ was higher than that of understanding father. In addition, parent-child problems have a significant negative impact on collaboration ability. For the 15-year-old group, the five variables of understanding father, punishing father, understanding mother, punishing mother, and high parental expectations all had a stable and significant positive impact on a student's cooperative ability.

\section{Collaboration and Life}

In terms of education, empathy, trust, and cooperation had positive effects on Chinese, Mathematics, and Art scores for 10-year-old students $(\mathrm{p}<0.01)$, but some effects were statistically insignificant, such as cooperation on mathematics score $(p=0.17)$ and empathy on art score $(p=0.17)$. Cooperation had 
a significant positive effect on educational expectation $(\mathrm{p}<0.01, \beta=0.07)$, but trust had a significant negative effect on educational expectation ( $\mathrm{p}<$ $0.01, \beta=0.06$ ). For the 15 -year-old group, cooperation has a significant positive impact on Chinese, Mathematics, and educational expectations. Additionally, trust has a significant positive effect on artistic achievement and educational expectations. From the perspective of global consciousness, both empathy and cooperation have significant positive effects on global consciousness, and the influence degree of empathy is higher than that of cooperation. However, trust has a significant negative impact on global consciousness, but the impact degree is relatively low. From the perspective of health variables, whether 10 years old or 15 years old, collaboration ability has a significant positive impact on students' self-health evaluation ( $\mathrm{p}<$ 0.01). From the perspective of subjective well-being, life satisfaction and test anxiety, empathy, trust, and cooperation have significant positive effects on students' subjective well-being and life satisfaction. They also seem to improve students' happiness and satisfaction. Trust and cooperation have negative effects on test anxiety, which can alleviate the anxiety caused by the test. For the 15-year-old group, empathy has a significant positive effect on subjective well-being and a significant negative effect on test anxiety; Trust has a significant positive effect on subjective well-being and life satisfaction, and a significant negative effect on test anxiety. Cooperation has significant positive effects on subjective well-being, life satisfaction, and test anxiety.

Therefore, strategies seeking to improve students' cooperation abilities should take a combined point and surface approach. The role of one or a type of factor should not be unilaterally emphasized but rather considered according to individuals, families, teachers, schools, and communities. Among other factors, understanding parenting and time spent online need more attention. In addition, the ability to cooperate has positive significance for the development of students' careers, but it still needs to be analyzed scientifically and objectively. Collaboration has a positive effect on some life outcome variables, but for other variables, such as students' academic performance, the results of the Suzhou analysis did not convey a completely positive signal.

Source: Journal of East China Normal University (Educational Sciences), 2021, 39(09): 62-76.

Correspondence to: Yipeng Tang 